\title{
Comparative effect of termiticides and plant extracts on mortality and tunnel formation of Odontotermes obesus
}

\author{
Muhammad Shahid Nisar ${ }^{1 *}$, Muhammad Amjad Bashir ${ }^{1}$, Hina Naz ${ }^{1}$ and \\ Sohail Ahmed ${ }^{2}$ \\ 1. Department of Plant Protection, Faculty of Agricultural Sciences, Ghazi University D.G. Khan-Pakistan \\ 2. Department of Entomology, University of Agriculture, Faisalabad-Pakistan \\ *Corresponding author's email: shahidnisar165@hotmail.com \\ Citation \\ Muhammad Shahid Nisar, Muhammad Amjad Bashir, Hina Naz and Sohail Ahmed. Comparative effect of \\ termiticides and plant extracts on mortality and tunnel formation of Odontotermes obesus. Pure and Applied \\ Biology. Vol. 9, Issue 3, pp1903-1910. http://dx.doi.org/10.19045/bspab.2020.90203
}

\begin{tabular}{llll}
\hline \hline Received: 05/02/2020 & Revised: 25/04/2020 & Accepted: 05/05/2020 & Online First: 22/05/2020
\end{tabular}

\section{Abstract}

Termites play a great role in recycling and decaying of materials but are serious threat to agricultural crops and buildings. There are various practices to control the termites like plant resistance, cultural, biological, physical barriers and synthetic chemicals. Most commonly, synthetic chemicals are used for their control. But the injudicious use of chemicals leads to serious environmental and health problems. Although insecticides of plant origin are safe alternatives to synthetic insecticides but due to their low potential they are not widely used and synthetic chemicals are still playing a great role in insect control. Many plant extracts have been found having anti-termitic properties. The present project was carried out in order to determine the comparative effect of termiticides and plant extracts on mortality and tunnel formation of Odontotermesobesus at Department of plant protection faculty of Agriculture, Ghazi University Dera Ghazi Khan. There were five treatments; two termiticides viz. Bifenthrin and Chlorfenapyr and three plant extracts (Dodonaea viscosa, Rhazya stricta and Citrullus colocynthis). Each treatment consisting of four concentrations i.e., $0 \%$ as a control, $1 \%, 5 \%$ and $10 \%$ was tested. The experiment was laid out in Completely Randomized Design and treatments were replicated three times. The data on mortality and tunnel formation was recorded at specific intervals and statistically analyzed by using Kaplan Meier test to determine $\mathrm{LT}_{50}$ values of termiticides and plant extracts. The results showed that Bifenthrin as most effective treatment among chemicals while among plant extracts Dodonaea viscosa was found most effective having lower $\mathrm{LT}_{50}$ values.

Keywords: Insecticides; Mortality; Plant extracts; Termites and Tunnel formation

\section{Introduction}

Termites are eu-social insects having welldefined system of morphological castes and division of labor in a colony $[1,2]$. They are widely known for their destruction capacity to wood and cellulose material of all types in tropics and sub-tropics [3]. A total of 2600 species of termites are reported all over the world. About 126 species of termites are known to feed on the mammalian dung and having significant role as recycler resulting in 
increased soil nutrients and aeration as a result of their foraging activity. Tunneling and nesting activities of the termites enhance microbial activity as well as improve chemical and physical properties of the soil depending upon the soil type, organic matter and moisture contents [4].

Termites cause severe damage to agriculture, natural reserves and historic places and have negative impact on economy [5]. There are significant losses caused by termites in annuals and perennial crop plants as well as structures $[6,7]$. Termites cause $90 \%$ damage to the tree plantationin forests and these are also responsible for the afla-toxins production in stored products which leads to secondary infection [8]. Odontotermes obesus, Microtermes obesi and Heterotermes indicola are economically important species in Pakistan [9].

The termite specie, Odontotermes obesus (Isoptera: Odontotermitidae) is known as highly destructive poly-phagous pest [10]. They attack all the major crops like maize, wheat, cotton, sugarcane, pulses, groundnut and trees such as silver oak and Eucalyptus. Agricultural crop yield is remarkably reduced due to termites' attack [11]. Termites cause $10-25 \%$ losses in field crops like wheat, maize, cotton, sugarcane, pulses and also in forests [12].

Various methods for the control of termites like physical, biological and chemical have been adopted [13]. Chemicals play a significant role in Integrated Pest Management (IPM) but the injudicious use of chemicals affect the non-target organisms and result in environmental deterioration and health problems $[\mathbf{1 4}, \mathbf{1 5}]$.

Despite their health and environmental concerns persistent chemicals are extensively used in Pakistan for the control of termites such as organophosphate, persistent organochlorine and synthetic pyrethroids [16]. Various studies have been done in order to determine the efficacy of new chemistry termiticides such as thiamethoxam, fipronil, indoxacarb, imidacloprid, chlorfenapyre, spinosad [17-21].

Biological alternatives are suitable alternatives to the chemicals [22]. Plant chemicals are important crop protectants in nature having less risk than synthetic chemicals which are toxic and undesirable [23]. They can be used for effective termites control as they are easily degradable and less expensive as compared to chemicals so practical and acceptable worldwide e.g. wild tobacco, neem and dried chili [24].

Although plant extracts are environment friendly and they suppress the termites infestation but still the use of chemicals is necessary due to low potential of plant extracts.

Keeping in view the importance of termites a laboratory trial was conducted to determine the effect of termiticides and plant extracts on mortality and tunnel formation of Odontotermes obesus.

\section{Materials and methods Experimental site}

The current experiment was conducted at Entomological Laboratory Department of Plant protection, Ghazi University Dera Ghazi Khan Punjab, Pakistan to compare the effect of termiticides and plant extracts on mortality and tunnel formation of termites

\section{Experimental layout}

The experiment was laid out in Completely Randomized Design (CRD) having five treatments with three replications.

\section{Collection of termites}

The workers and soldiers of termites' specie, Odontotermes obesus (Termitidae: Isoptera) were collected from corrugated cardboard in PVC monitors installed at different places in the field at Agriculture faculty, Ghazi University Dera Ghazi Khan where such specie was present abundantly.

\section{Treatments}

The experiment comprised of following treatments: 


\section{Termiticides}

T1: Bifenthrin 10EC

T2: Chlorfenapyr 40EC

\section{Plant materials}

T3: Rhazyastricta (Leaves)

T4: Dodonaea viscosa (Snatha, Leaves)

T5: Citrullus colocynthis (Kortumma Fruits)

Preparation of termiticides solution

According to active ingredient $0 \%, 1 \%, 5 \%$, and $10 \%$ solution of termiticides were prepared.

\section{Extraction method}

Extracts of the plants were obtained in following manner:

Fresh and fully developed leaves of Rhazyastricta and Dodonaea Viscosa plants and fruits of Citrullus colocynthis were collected from the field area of Agriculture faculty, Ghazi University Dera Ghazi Khan. After washing with tape water, leaves and fruits of the plants were shade-dried and were grinded into powder form.

\section{Aqueous extracts of leaves}

One hundred gram powder of each plant was extracted in $200 \mathrm{ml}$ of water in ratio of 1:2 $(\mathrm{w} / \mathrm{v})$. Extracts were kept at room temperature for 72 hours and shaken well at different intervals. After this, filtration of the extract was done by Whatman filter No. 2 . This procedure was repeated twice to obtain maximum extracts. All the extractable were pooled and solid extract was obtained by evaporating water at room temperature. Further this was used for the preparation of required concentration.

Bioassay by treating soil with Termiticides and plant extracts

\section{Soil preparation}

Soil was taken from the field of termite collection and was sieved through 30-mesh screen. Water was also added in the soil to avoid mortality due to dehydration.

\section{Soil bioassay}

Anti-termite Sugarcane Strip Bioassay (ASSB) was done in Petri dishes of $8.75 \mathrm{~cm}$ diameter and $1.5 \mathrm{~cm}$ height having sifted soil and strips of sugarcane $(1.5 \mathrm{~cm} \times 6.0 \mathrm{~cm})$ as food of termites. Different concentrations of termiticides and plant extracts were mixed in soil having sugarcane strips in Petri dishes. Some water was added into soil to keep the soil moist for avoiding death of termites due to dehydration. Fifty active termite workers were released in each Petri dish. Data for mortality was recorded after an interval of 2 hours (reading after 2, 4, 6,8,10 and 12 hours during first day) and later after every 12 hours until the mortality of the workers occurred. Same procedure was done regarding the control experiment without any termiticides and plant extracts chemical.

Effect of termiticides and plant extracts on tunnel formation by termites

Tunnels made by termites during foraging showed the response of termites towards termiticides and plant extracts at different concentrations. Tunnel formation was recorded after 5, 10 and 15 hours and measured in $\mathrm{mm}^{2}$ with planimeter. Control treatment was without termiticides and plant extracts.

\section{Statistical analysis}

Kaplan Meiyer survival test was used to obtain Lethal Time of $50 \%$ population (LT 50) of different chemicals and plant extracts at various concentrations.

The mean tunnel length in different treatments at various concentrations was compared by ANOVA through Least Significant Difference test (LSD).

\section{Results}

\section{Mortality of Odontotermes obesus}

According to (Table 1), $\mathrm{LT}_{50}$ value increases with the decrease in concentration. The $\mathrm{LT}_{50}$ values for Bifenthrin at the concentrations (10\%, 5\%, $1 \%$ and $0 \%$ ) were 305.986, $322.000, \quad 338.000$ and 503.952 hours respectively. For Chlorfenapyr application, $\mathrm{LT}_{50}$ values at the $10 \%, 5 \%, 1 \%$ and $0 \%$ concentrations were 310.000, 322.000, 340.000 and 497.956 hours respectively. For Rhazya stricta plant extract, the $\mathrm{LT}_{50}$ values 
at $10 \%, 5 \%, 1 \%$ and $0 \%$ concentration were 406.000, 434.000, 472.000 and 521.956 hours respectively. The $\mathrm{LT}_{50}$ values for Dodonaea viscose plant extract at the concentrations $(10 \%, 5 \%, 1 \%$ and $0 \%)$ were $363.964,389.980,405.956$ and 521.660 hours respectively. At 10\%, 5\%,1\% and $0 \%$ concentrations of Citrullus colocynthis, $\mathrm{LT}_{50}$ values were 430.000, 468.000, 508.000 and 574.000 hours respectively. The highest mortality of the termites $O$. obesus was caused by Bifenthrin (T1) followed by Chlorfenapyr (T2), Dodonaea viscose (T4), R. stricta (T3) and Citrullus colocynthis (T5) @ 10\% concentration with the $\mathrm{LT}_{50} 305.986$, $310,406,363.964$ and 430 respectively.

Table 1. Comparison of $\mathrm{LT}_{50}$ values in different concentrations of treatments against Odontotermes obesus

\begin{tabular}{|c|c|c|c|c|}
\hline \multirow{2}{*}{ Treatments } & Time Interval & \multicolumn{3}{|c|}{ Concentrations } \\
\cline { 2 - 5 } & (Hours) & $\mathbf{1 \%}$ & $\mathbf{5 \%}$ & $\mathbf{1 0 \%}$ \\
\hline \multirow{3}{*}{ Bifenthrin } & Time 1 & $2 \mathrm{a}$ & $2 \mathrm{a}$ & $1.5 \mathrm{a}$ \\
\cline { 2 - 5 } & Time 2 & $4.25 \mathrm{a}$ & $4.25 \mathrm{a}$ & $4 \mathrm{a}$ \\
\cline { 2 - 5 } & Time 3 & $5.75 \mathrm{a}$ & $5.75 \mathrm{a}$ & $5.5 \mathrm{a}$ \\
\hline \multirow{3}{*}{ Chlorfenapyr } & Time 1 & $3.25 \mathrm{a}$ & $3 \mathrm{a}$ & $2.25 \mathrm{a}$ \\
\cline { 2 - 5 } & Time 2 & $5.25 \mathrm{a}$ & $4.75 \mathrm{a}$ & $4.25 \mathrm{a}$ \\
\cline { 2 - 5 } & Time 3 & $6.75 \mathrm{a}$ & $6 \mathrm{a}$ & $6 \mathrm{a}$ \\
\hline \multirow{3}{*}{ Dhazyastricta } & Time 1 & $4 \mathrm{c}$ & $4 \mathrm{~b}$ & $3.75 \mathrm{~b}$ \\
\cline { 2 - 5 } & Time 2 & $6.75 \mathrm{~b}$ & $6.75 \mathrm{a}$ & $6.75 \mathrm{ab}$ \\
\cline { 2 - 5 } & Time 3 & $4.9 \mathrm{a}$ & $8.5 \mathrm{a}$ & $8.5 \mathrm{a}$ \\
\hline \multirow{3}{*}{ Citrulluscolocynthis } & Time 1 & $4.5 \mathrm{~b}$ & $4.25 \mathrm{c}$ & $3.25 \mathrm{~b}$ \\
\cline { 2 - 5 } & Time 2 & $6.25 \mathrm{ab}$ & $7.5 \mathrm{~b}$ & $6 \mathrm{ab}$ \\
\cline { 2 - 5 } & Time 3 & $8 \mathrm{a}$ & $9.5 \mathrm{a}$ & $8.5 \mathrm{a}$ \\
\cline { 2 - 5 } & Time 1 & $5.25 \mathrm{c}$ & $4.5 \mathrm{~b}$ & $3 \mathrm{~b}$ \\
\cline { 2 - 5 } & Time 2 & $7.75 \mathrm{~b}$ & $7.75 \mathrm{a}$ & $8.7 \mathrm{a}$ \\
\hline
\end{tabular}

\section{Tunnel formation of $O$. obesus}

Non-significant differences occurred among different time intervals of all concentrations $(1 \%, 5 \%$ and $10 \%)$ of Bifenthrin application (Table 2). Similarly, non-significant variation was also observed at all concentrations of Chlorfenapyr among various time intervals. In case of $R$. stricta plant extract application highly significant (4\%) was significantly varied than Time 2 $(6.75 \%)$ and Time 3 (8.5\%). Tunnel formation on $10 \%$ concentration was increased at Time 3 and Time 2 intervals $(8.5 \%$ and $6.75 \%)$ respectively while minimum $(3.75 \%)$ at Time 1 interval. In case of Dodonaea viscosa plant extract application increases the tunnel formation was recorded at Time 3 interval (8\%), Time variation was observed at all concentrations. At $1 \%$ concentration, tunnel formation after 5 hours (Time 1) was decreased (4\%) as compared to other time intervals (Time 2 and Time 3). After 10 hours (Time 2) of treatment application, tunnel formation was increased $(6.75 \%)$ while after 15 hours (Time 3) the tunnel formation was reduced $(4.9 \%)$. At $5 \%$ concentration, tunnel formation at Time 1

2 interval $(6.25 \%)$ and Time 1 interval (4.5\%) at $1 \%$ concentration. Highly significant differences were observed at Time1 (4.25\%), Time $2(7.5 \%)$ and Time3 (9.5\%) intervals on $5 \%$ concentration. Lowest tunnel formation was recorded at Time 1 interval $(3.25 \%)$ while highest tunnel formation was at Time 3 interval $(8.5 \%)$ and Time 2 interval $(6 \%)$ respectively. In case of Citrullus colocynthis 
plant extract application, highly significant variation was recorded among time intervals (Time 1, 2 and 3 ) at $1 \%$ concentration. Statistically similar results were recorded in Time $2(7.75 \%)$ and Time $3(9.5 \%)$ intervals on $5 \%$ concentration. Reduced tunnel formation was recorded on $10 \%$ concentration in Time 1 interval $(3 \%)$ while Time $2(5.7 \%)$ and Time $3(8.25 \%)$ showed statistically similar results.

Table 2. Comparison of time interval $(\mathrm{H})$ of tunnel formation of Odontotermes obesus within the concentration after treatments application

\begin{tabular}{|c|c|c|}
\hline Treatments & Concentrations & LT $_{\mathbf{5 0}}$ (Hours) $\mathbf{\text { S.E }}$ \\
\hline \multirow{4}{*}{ Bifenthrin } & $0 \%$ & $503.952 \pm 7.320$ \\
\cline { 2 - 3 } & $1 \%$ & $338.000 \pm 12.805$ \\
\cline { 2 - 3 } & $5 \%$ & $322.000 \pm 13.215$ \\
\cline { 2 - 3 } & $10 \%$ & $305.986 \pm 13.616$ \\
\cline { 2 - 3 } & $0 \%$ & $497.956 \pm 7.587$ \\
\cline { 2 - 3 } & $1 \%$ & $340.000 \pm 12.752$ \\
\cline { 2 - 3 } & $5 \%$ & $322.000 \pm 13.215$ \\
\hline \multirow{3}{*}{ Rhazya stricta } & $10 \%$ & $310.000 \pm 13.514$ \\
\cline { 2 - 3 } & $0 \%$ & $521.534 \pm 6.639$ \\
\cline { 2 - 3 } & $1 \%$ & $472.000 \pm 8.635$ \\
\cline { 2 - 3 } & $5 \%$ & $434.000 \pm 9.996$ \\
\cline { 2 - 3 } & $10 \%$ & $406.000 \pm 10.891$ \\
\cline { 2 - 3 } & $0 \%$ & $521.660 \pm 6.582$ \\
\cline { 2 - 3 } & $1 \%$ & $405.956 \pm 10.904$ \\
\hline \multirow{3}{*}{ Codonaea viscosa } & $5 \%$ & $389.980 \pm 11.377$ \\
\cline { 2 - 3 } & $10 \%$ & $363.964 \pm 12.118$ \\
\cline { 2 - 3 } & $0 \%$ & $574.000 \pm 2.108$ \\
\cline { 2 - 3 } & $1 \%$ & $508.000 \pm 7.107$ \\
\cline { 2 - 3 } & $5 \%$ & $466.000 \pm 8.864$ \\
\hline \multirow{3}{*}{ Citrullus colocynthis } & $10 \%$ & $430.000 \pm 10.129$ \\
\hline
\end{tabular}

\section{Discussion}

The highest mortality was obtained by the insecticide Bifenthrin followed by Chlorfenapyr, Dodonaea viscose, Rhazya stricta and Citrullus colocynthis. The highest mortality was caused by Bifenthrin @ 10\% concentration with the lowest $\mathrm{LT}_{50}$ which was recorded 305.986. The reason is that Bifentrhin has repellant effect. The results are in accordance with the findings of [25] who reported that the efficacy is dose dependant and Bifenthrinalso has repellent effect so its toxicity is more as compared to other treatments.

Natural products have been used by many researchers against different insect pests. Trachyspermum ammi also have much insecticidal and termiticidal effects. The clove bud oil and garlic oil had potent antitermitic activity.

Extracts from leaves of Azadirachta excels, extracted with solvents, acetone, methanol, aqueous and petroleum ether were tested on subterranean termite, Coptotermes curvignathus. The termite workers responded differently to soils treated with varying concentrations of the extracts. The termites became insensitive towards the extracts upon a longer period of exposure. The results showed that extracts from $A$. excels leaves had an inhibitory effect on subterranean termites, $C$. curvignathus. The soils treated 
with the extracts did pose a hindrance to the tunneling activities of the termites [26].

Effects of hexane, ethanol, and petroleum ether extracts of the black pepper fruits, Piper nigrum L. were studied on the dry wood termite, Cryptotermes brevis. The hexane extracts had excellent efficacy against the insect. [27] Plant extracts (either aqueous or polar organic solvent extracts) can also kill or repel insects, mites and nematodes.

Our results are in favor with the results of [28] that studied the laboratory evaluation of Bifenthrin 10 EC, Imidacloprid $50 \mathrm{SC}$, Chlorpyrifos 40 EC Thiamethoxam 70WS, Flufenoxuron $10 \mathrm{DC}$ and Thiamethoxam 70WS against Microtermesobesiin three different soils from Layyah, Faisalabad and Chakwal.The mortality of termites increased with increase in concentrations and toxic effects of termiticides were same for both topical application method and in the method of termiticides mixed with soil. Chlorpyriphos was proved to be best from all the insecticides. [29] Also evaluated the efficacy of Chlorpyrifos 40 EC @ 1000 ml acre $^{-1}$, Monomehypo $5 \mathrm{G} @ 9 \mathrm{~kg} \mathrm{acre}^{-1}$ and Imidacloprid 25 WP @250g acre ${ }^{-1}$ on subterranean termites in sugarcane field. Chlorpyrifos showed maximum control against termite's population. [30] Evaluated the effect of seven termiticides viz., Fipronil, Bifenthrin, Chlorantraniliprole, Cyantraniliprole, Imidacloprid, Chlorfenapyr and Indoxacarb on the basis of $\mathrm{LD}_{50}$ and $\mathrm{LC}_{50}$ against the three subterranean termite species. Out of above seven mentioned termiticides lethal toxicity of Fipronil was high for Coptotermes formosanus and Reticulitermes flavipes and Imidacloprid has low lethal toxicity for both the species.

Kausar et al. [31] studied the efficacy of soil barrier, insecticides and foraging activities of termites in farm building. Foraging activities of termites were observed by installing PVC pipes in soil which was high from mulberry plantation than follow field side toward the building. Soil barrier of the insecticides from bioassay test was created around a pit $(0.48$ $\mathrm{m}, 0.32 \mathrm{~m}$, width and $0.4 \mathrm{~m}$ deep) inside Entomological Research Laboratories. Soil barrier prevented the penetration of the insecticides mixed soil for only up to 25 days. Chlorpyrifos and Alpha Cypermethrin provided effective control against termites at concentration of $1200 \mathrm{ppm}$ after three hours but Chlorpyriphos alone also showed brilliant results against termites. Foraging activities of termites were less where these insecticides were applied.

\section{Conclusion}

Laboratory bioassays with different insecticides in particular indicated the potential of some of them as a good termiticides. Bifenthrin was more toxic as compared to other tested insecticides because the $\mathrm{LT}_{50}$ values of bifenthrin were lower in all the concentration used against Odontotermes obesusin soil.

\section{Authors' contributions}

Conceived and designed the experiments: MS Nisar \& S Ahmed, Performed the experiments: H Naz, Analyzed the data: MA Bashir \& MS Nisar, Contributed reagents/ materials/ analysis tools: MA Bashir \& MS Nisar, Wrote the paper: H Naz \& MS Nisar.

\section{References}

1. Hattori A, Sugime Y, Sasa C, Miyakawa H, Ishikawa Y, Miyazaki S, Okada Y, Cornette R, Lavine LC, Emlen DJ, Koshikawa S \& Miura T (2013). Soldier Morphogenesis in theDamp-Wood Termite Is Regulatedby the Insulin Signaling Pathway. J Exp Zool (Mol Dev Evol) 320: 295-306.

2. Peralta RCG, Menezes EB, Carvalho AG \& Aguiar-Menezes EL (2004). Wood consumption rates of forest species by subterranean termites (Isoptera) under field conditions. Revista Arvore 28(2): 283-289.

3. Cornette $\mathrm{R}$, Matsumoto $\mathrm{T} \&$ Miura $\mathrm{T}$ (2007). Histological Analysis of Fat 
Body Development and Molting Events During Soldier Differentiation in the Damp-WoodTermite, Hodotermopsis sjostedti (Isoptera, Termopsidae). Zool Sci 24: 1066-1074.

4. Freymann, BP, Buitenwerf R \& Desouza O (2008). The importance of termites (isoptera) for the recycling of herbivore dung in tropical ecosystems: A review. Eur J of Ento 105: 165-173.

5. Rashid M, Garjan AS, Naseri B \& Saberfar F (2012). Comparative toxicity of five insecticides against subterranean termite, Amitermesvilis (Isoptera: Termitidae) under laboratory conditions. Mun Ent Zool 7(2): 1044-1050.

6. Guan YQ, Chen J, Tang J, Yang L \& Liu JM (2011). Immobilizing bi-fenthrin on wood for termite control. Int Biodete \& Biodegr 65(3): 389-395.

7. Verma M, Sharma S \& Prasad R (2009). Biological alternatives for termite control. A review. Int Biodete \& Biodegr 63(8): 959-972.

8. Osipitan AA \& Oseyemi AE (2012). Evaluation of the bio-insecticidal potential of some tropical plant extracts against termite (Termitideae:Isoptera) in Ogun State, Nigeria J Entomol 9(5): 257-265.

9. Manzoor F, Malik SA, Naz N, Cheema KJ \& Naz S (2012). Potential of antitermitic activities of eucalyptus oil. Pak J Zool 44(2): 335-339.

10. Upadhyay RK, Jaiswal G, Ahmad S, Khanna L \& Jain SC (2012). Antitermite Activities of $C$. decidua Extracts and Pure Compounds against Indian White Termite Odontotermesobesus (Isoptera: Odontotermitidae). Psyche $J$ Entomol 8(4): 510-514.

11. Upadhyay RK (2013). Effects of plant latex based anti-termite formulations on Indian white termite Odontotermesobesus (Isoptera: Odontotermitidae) in sub-tropical high infestation areas. Op J of Ani Sci 3: 281294.

12. Rajagopal D (2002). Economically important termite species in India. Sociobiol 41: 33-46.

13. Addisu S, Mohammed D \& Waktole S (2014). Efficacy of Botanical Extracts against Termites, Macrotermes spp., (Isoptera: Termitidae) Under Laboratory conditions. Int J of Agri Res 9: 60-73.

14. Ahmed S, Mustafa T, Riaz MA \& Hussain A (2006). Efficacy of insecticides against subterranean termites in sugarcane.Int. J Agric Biol 8(4): 508-510.

15. Remmen LN \& Su NY (2005). Time trends in mortality for thiamethoxam and fipronil against Formosan subterranean termites and eastern subterranean termites (Isoptera: Rhinotermitidae). $J$ Eco Ent 98(3): 911-915.

16. Hu XP (2005). Evaluation of efficacy and non-repellency of indoxacarb and fipronil-treated soil at various concentrations and thicknesses against two subterranean termites (Isoptera: Rhinotermitidae). J Eco Ento 98(2): 509517.

17. Wang X, Wei J, Mo J, W. Mao \& Ye T (2007). The susceptibility of Reticulitermeschinensis (Isoptera: Rhinotermitidae) to sulfluramid, imidacloprid and ivermectin. Sociobiol 50: $1-12$.

18. Iqbal N \& Saeed S (2013). Toxicity of Six New Chemical Insecticides against the Termite, Microtermesmycophagus D. (Isoptera: Termitidae: Macrotermitinae). Pak J Zool 45(3): 709-713.

19. Ripa R, Luppichini P, Su NY \& Rust MK (2007). Field evaluation of potential control strategies against the invasive eastern subterranean termite (Isoptera: Rhinotermitidae) in Chile $J$ of Eco Ento 100: 1391-1399. 
20. Vargo EL \& Parman V (2012). Effect of fipronil on subterranean termite colonies (Isoptera: Rhinotermitidae) in the field. $J$ Econ Entomol 105(2): 523-532.

21. Nisar MS (2012). Effect of plant extracts on the behaviour and physiology of the Odontotermes obesus (Ramb.) (Isoptera: Termitidae). PhD thesis Department of Agriculture Entomology University of Agriculture, Faisalabad, Pakistan.

22. Anonymous (2000). Learning to Cut the Chemicals in Cotton. Pesticide Action Network (PAN) UK, Eurolink Centre, London pp 91.

23. Yeoh BH \& Lee CY (2007). Tunneling activity, wood consumption and survivorship of Coptotermes gestroi, Coptotermes curvignathus and Coptotermes kalshoveni (Isoptera: Rhinotermitidae) in the laboratory. Sociobiol 50: 1087-1096.

24. Sajap AS \& Aloysius F (2000). Effects of leaf extracts of Azadirachtaexcelsa on Coptotermescurvignathus (Isoptera: Rhinotermitidae). Sociobiol 36(3): 497503.

25. Moein,S I \& Farrag RM (2000). Susceptibility of the dry-wood termite Cryptotermesbrevis Walker to the black pepper extracts. Egyptian J of Agri Rese 78(3): 1135-1140.

26. Ahmed S \& Farhan M (2006). Laboratory evaluation of chlorpyrifos, bifenthrin, imidacloprid, thiamethoxam and flufenoxuron against Microtermesobesi (Isoptera: Termitidae). Pak Entomol 28: 45-50.

27. Mao L, Henderson G \& Scherer CW (2011). Toxicity of seven termiticides on the Formosan and eastern subterranean termites. J Eco Entomol 104(3): 10021008.

28. Ahmed S \& Qasim M (2011). Foraging and chemical control of subterranean termites in a farm building at Faisalabad. Pakistan. Pak J life soc Sci 9(1): 58-62.

29. Naeem I, Alvi AM, M., Shoaib. M, A. Rashid A, Saeed Q \& Bashir MA (2018). Evaluation of different wood species against fungus-growing termite Odontotermes obesus (Blattodea: Termitidae: Macrotermitinae) for using in bait stations. $J$ of Asia Paci Entomo 21: 485-489.

30. Alvi AM, Iqbal N, Bashir MA, Rahmani MIA, Z. Ullaha U, Saeed Q, and Latif A (2017). Efficacy of Rhazya stricta leaf and seed extracts against Rhyzopertha dominica and Trogoderma granarium. Kuwait J Sci 45(3): 1-10.

31. Kausar R, Bashir MA, Nisar S, Rehamani MIA, Hashami SA \& Atta S (2017). Eco-Friendly Management of Pulse Beetle (Callosobruchus chinensis) By Using Different Plant Materials. Asian J Agri \& Biol 5(2):70-77. 